\title{
MODELING, SIMULATION AND ANALYSIS OF DISTURBANCES AND DEFECTS IN LOW VOLTAGE INSTALATIONS
}

\author{
B. BOTEA ${ }^{1}$. I. MARINESCU ${ }^{2}$, C. DRĂGOI ${ }^{3}$, H. ANDREI ${ }^{4}$ \\ ${ }^{1} \mathrm{PhD}$ student, University Valahia of Târgoviște, ${ }^{2} \mathrm{PhD}$ student, University Valahia of Târgoviște, ${ }^{3} \mathrm{PhD}$ student, \\ University Valahia of Târgoviște, Dep. Of Electronics and Power Systems, ${ }^{4}$ Prof. University Valahia of Târgoviște, \\ Doctoral School of Engineering Sciences \\ E-mail: bvbotea@gmail.com, ioan.marinescu@yahoo.com, catalin_dragoi18@yahoo.com, horia.andrei@valahia.ro
}

\begin{abstract}
In this article we present some simulation models regarding the occurences that affect the quality of the electricity supplied to a low voltage consumer. We believe that these will offer to the researcher the opportunity to simulate power quality deviations in different energy system models, thus providing a picture regarding the way those deviations propagate and behave, creating a few basic patterns for studying the energy quality, also taking into consideration the limitations of the system in respect to the software used and the human factor performing the research.
\end{abstract}

Keywords: simulation, defects, disturbances, low voltage, energy quality.

\section{INTRODUCTION}

There are currently a large number of tools for simulating power supply systems. Among these, the most commonly used simulation environments in the academic environment are: the ATP version of the Electromagnetic Transients Program (EMT) simulator [1-5], the PSCAD (Power Systems CAD) simulator with EMTDC (Electromagnetic Transients including DC) [6-10], MATLAB with the Power System Toolbox [11-15] and the Power System Analysis Toolbox [16-23] and Simulink with SimPowerSystems [24-36] and Power Analysis Toolbox [37-40].

Article [41] provides a full description of the benefits offered by each simulator.

Circuits will be simulated in the MATLAB / Simulink environment with the SimPowerSystems module. These circuits are based on the circuit of Figure 1 and have been developed from the schemes presented in [27].

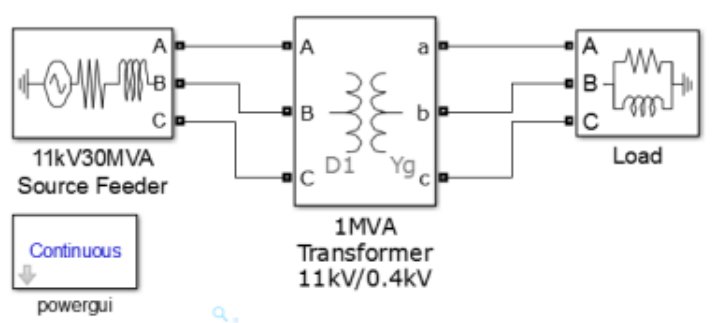

Figure 1. Basic circuit used for simulations
The circuit in Figure 1 contains a $11 \mathrm{kV}$ three phase (which will be represented in the article by symbol " $\Phi "$ ) $\Phi$ source module that can supply $30 \mathrm{MVA}$ at a frequency of $50 \mathrm{~Hz}$, a $11 / 0.4 \mathrm{kV}$ transformer module with a power of up to $1 \mathrm{MVA}$ and an inductive load module with an active power of $10 \mathrm{~kW}$ and a reactive power of $100 \mathrm{VAR}$. At simulation, the powergui module is used continuously with the ode23tb solver.

\section{SHORT CIRCUIT MODE}

To simulate the short circuit, two fault simulation modules are connected to the diagram in Figure 1. The first such module is called Fault and allows simulation of a short-circuit event in which one or more $\Phi$ lines have been accidentally connected. The second module, Multistage Fault, allows simulation of a second shortcircuit event. The configuration menus of these modules are shown in Figure 2. Two circuits connected to two oscilloscope modules have been added to the circuit, obtaining the circuit shown in Figure 3. In this section, the simulation duration was set to $0,4 \mathrm{~s}$, and the short circuit takes place at $0.1 \mathrm{~s}$ and lasts $0.2 \mathrm{~s}$.

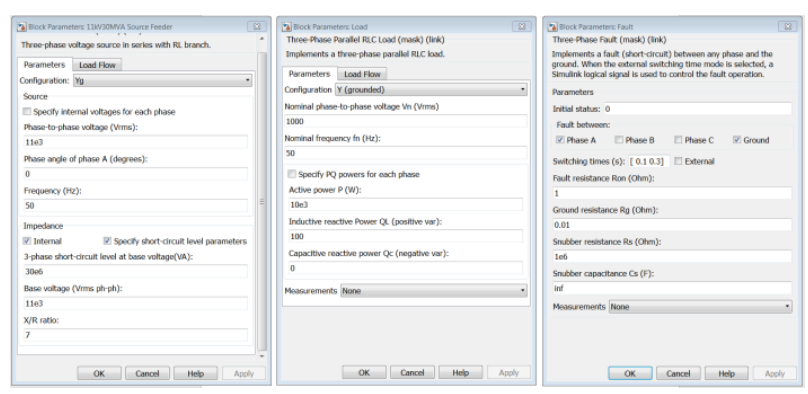

Figure 2. Configuration of the blocks used in the simulation

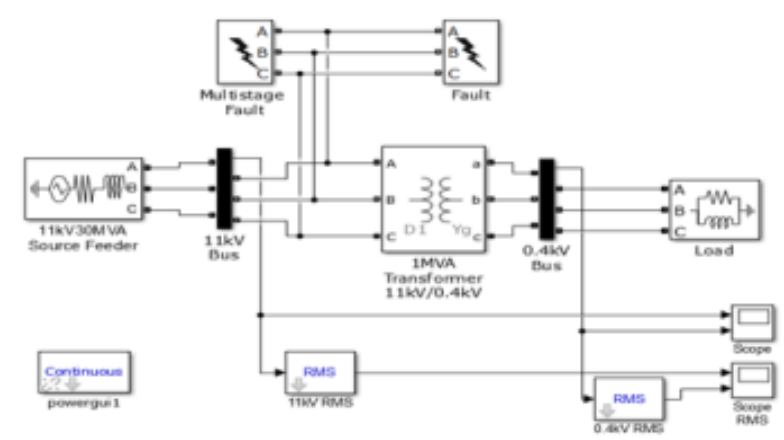

Figure 3. Circuit to simulate short circuit 
The results of the simulation are shown in Figures 4-5. Next, the voltage corresponding to $\Phi$ A will be represented in blue, with the one corresponding to $\Phi$ B and green for $\Phi \mathrm{C}$. The first set of results is shown in figures 4.a and 5.a, simulating a short-circuit between $\Phi$ $\mathrm{A}$ and null before the transformer, on the $11 \mathrm{kV}$ bus. These results correspond to the configuration in Figure 2. It is noted that the simulated short circuit has lowered the effective phase voltage from $\Phi$ A from 6.35 to $1.47 \mathrm{kV}$. This voltage gap affects both the A $\Phi$ (from $230 \mathrm{~V}$ to 116 $\mathrm{V}$ ) and the $\mathrm{C} \Phi$ (from $230 \mathrm{~V}$ to $164 \mathrm{~V}$ ) to the consumer. The effects on the $\Phi$ B after the transformer (on the 0.4 $\mathrm{kV}$ bus) are negligible.

In the next experiment (Figures 4.b and 5.b) a short circuit between Phase A and Phase B is simulated.

The effective voltage on the $6.35 \mathrm{kV}$ lines decreases to $4.38 \mathrm{kV}$ for Phase A and $2.04 \mathrm{kV}$ for Phase B At the consumer, this short circuit led to $\Phi \mathrm{A}$ at $53 \mathrm{~V}, \Phi \mathrm{B}$ at $175 \mathrm{~V}$ and $\Phi \mathrm{C}$ at $225 \mathrm{~V}$.

There is also a small oscillation (line voltage at phase C reaching a maximum of $244 \mathrm{~V}$ ). These oscillations are due to short-circuit phase changes.
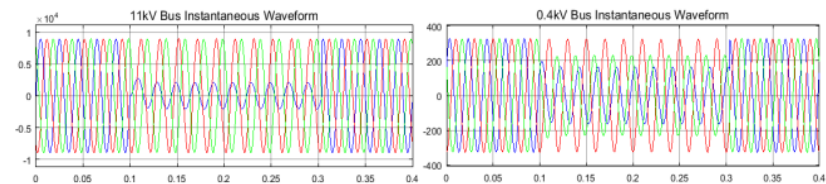

(a) Single-phase short-circuit between $\Phi$ A and null

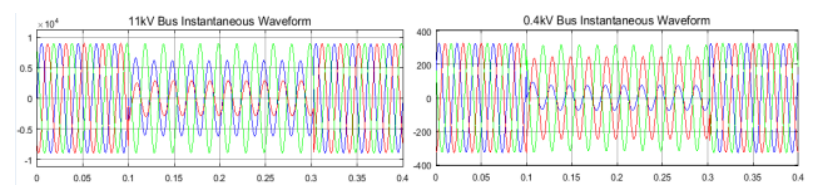

(b) Biphasic short circuit between $\Phi$ A and $\Phi$ B

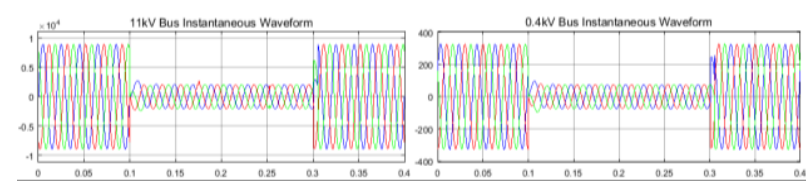

(c) Biphasic short circuit between $\Phi$ A, $\Phi$ B and null

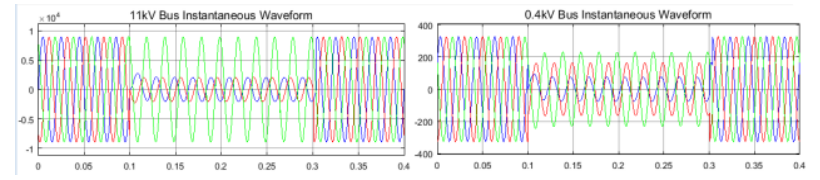

(d) Three- $\Phi$ short-circuit between $\Phi A, \Phi B$ and $\Phi C$

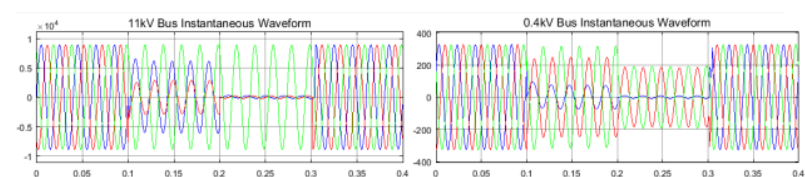

(e) Short series: between $\Phi$ A and $\Phi$ B, then between A, B and null

Figure 4. Instantaneous value of line voltages before and after the transformer when short circuit occurs

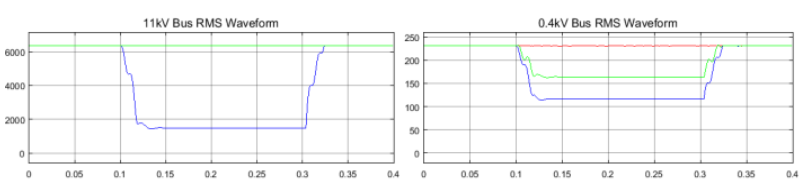

(a) Short-circuit single phase $\Phi$ A and null

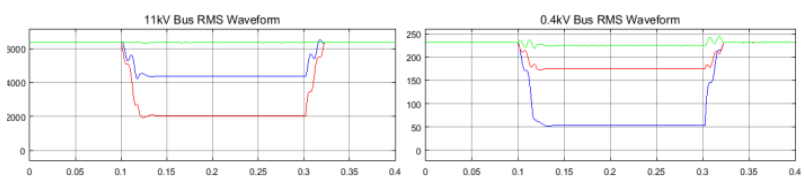

(b) Biphasic short circuit between $\Phi$ A and $\Phi$ B

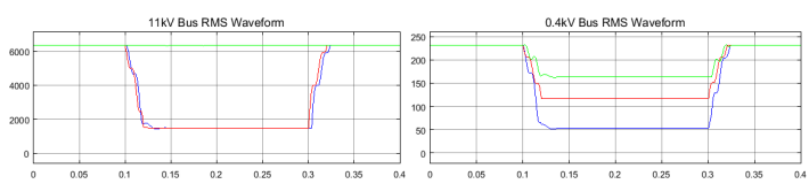

(c) Biphasic short circuit between $\Phi$ A, $\Phi$ B and null

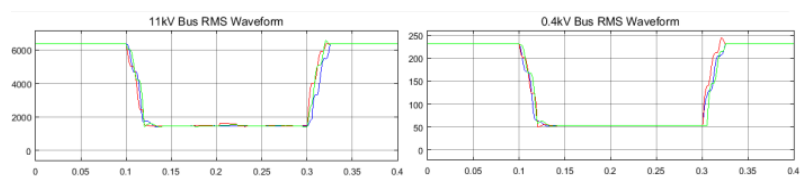

(d) Three-phase short-circuit between $\Phi$ A, $\Phi$ B and $\Phi$ C

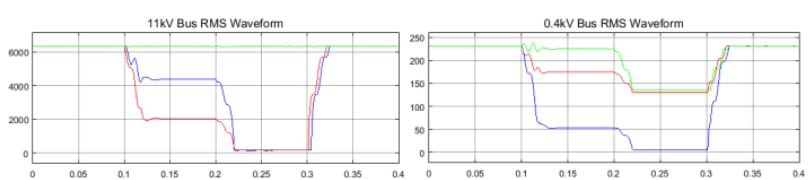

(e) Short series: between $\Phi$ A and $\Phi$ B, then between A, B and null

Figure 5 Actual value of line voltages before and after the transformer in short-circuit

Figures 4.c and 5.c show the effects of a short circuit between $\Phi \mathrm{A}, \Phi \mathrm{B}$ and null. The line voltages in phases A and $\mathrm{B}$ are at $1.47 \mathrm{kV}$ before passing through the transformer. At the consumer, all three phases are affected: $\mathrm{A}$ is at $53 \mathrm{~V}, \mathrm{~B}$ is $117 \mathrm{~V}$, and $\mathrm{C}$ is at $164 \mathrm{~V}$.

In Figures 4.d and 5.d we have a short circuit between all three phases. Before the transformer, the voltages reach the value of $1.47 \mathrm{kV}$, corresponding to a voltage gap of $53 \mathrm{~V}$ after the transformer.

The last set of graphs (Figures 4.e and 5.e) simulates the effect of short-circuits that take place successively.

The first event takes place from $0.1 \mathrm{~s}$ : a short circuit between $\Phi \mathrm{A}$ and $\Phi \mathrm{B}$, then 0.2 second starts the second event: short-circuit between $\Phi$ A, $\Phi$ B and $\Phi$ B.

At the second event, the short-circuit loop impedance is lowered to $0.1 \Omega$. The line voltage during the first event is the same as in figures 4.b and 5.b.

At the second event, the decrease in the impedance in the short-circuit loop caused a more significant voltage gap, i.e. an effective consumer voltage of $5.1 \mathrm{~V}$ per phase $\mathrm{A}$ and around $130 \mathrm{~V}$ on the $\mathrm{B}$ and $\mathrm{C}$ phases. 


\section{OVERLOADS CAUSED BY A LIGHTNING STRIKE}

The circuit in Figure 6 simulates transient overvoltages caused by a lightning strike near the transmission lines. The MATLAB / Simulink environment does not have a dedicated model for this phenomenon, so it is necessary to create a simulation block.

Figure 6.b shows the lightning strike simulation subcircuit that forms the desired pattern. In this sub-circuit, the MATLAB function block contains the waveform generation code of the light pulse generated by lightning:

$$
\begin{aligned}
& \text { function } \mathrm{v}=\underset{\text { lightning_function }(\mathrm{t}, \mathrm{t} 1, \mathrm{~A}, \mathrm{u})}{\text { alpha }=14000} \\
& \qquad \mathrm{v}=\mathrm{A} * \exp (-\operatorname{alpha} * \operatorname{abs}(\mathrm{t}-\mathrm{t} 1)) * \mathrm{u}
\end{aligned}
$$

where $\mathrm{A}$ is the magnitude of the pulse (read from variable mag, variable controlled from the module properties, set to $1 \mathrm{kV}$ in the current experiment), $\mathrm{t} 1$ is the start time of the pulse (set at $0.0125 \mathrm{~s}$ ), and alpha represents the damping factor set to 14000). The impulse generation code also contains the MATLAB functions $\exp (a)=e^{a}$ (exponential function) and

$$
a b s(a)=\left\{\begin{array}{l}
a, \text { daca } a \geq 0 \\
-a, \text { daca } a<0
\end{array}\right. \text { (function module). }
$$

The lightning strike simulation block is connected to the circuit through a $10 \Omega$ and $1 \mu \mathrm{H}$ connection. The impedance value controls the simulated distance between the lightning strike and the electrical network. This distance influences in turn the amplitude of the transient overvoltage introduced into the circuit (the smaller the impedance value, the lighter hit closer to the simulated grid).

Figure 7 shows the effect of the simulated lightning strike with the parameters above.

The $1 \mathrm{kV}$ impulse affected all three phases, the disturbance of $0.0125 \mathrm{~s}$ being clearly visible in the graph.

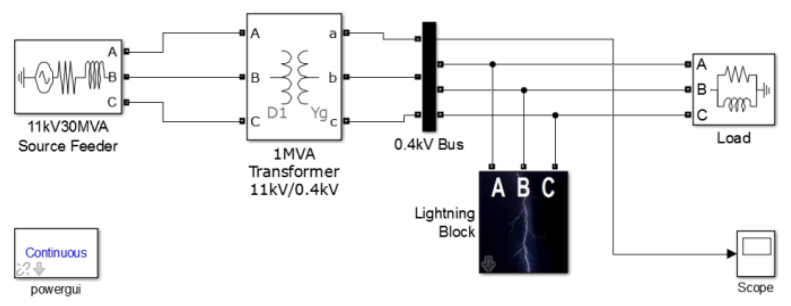

a) Main circuit

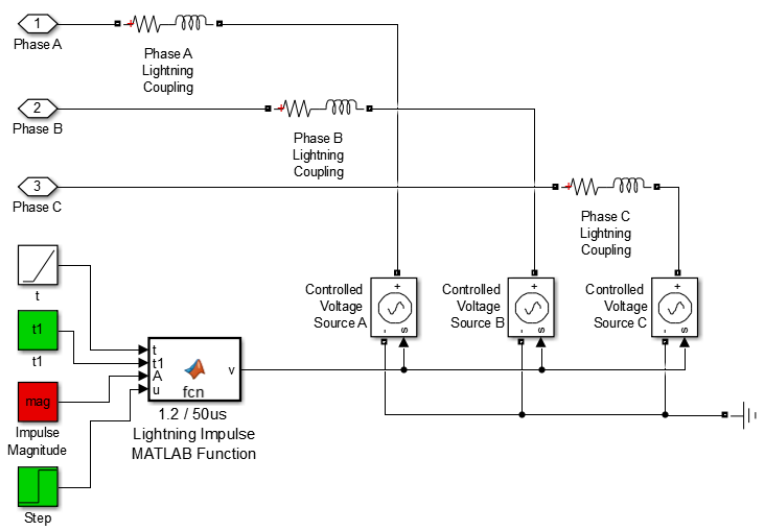

(b) The lightning subcircuit

Figure 6. The lightning strike simulation circuit

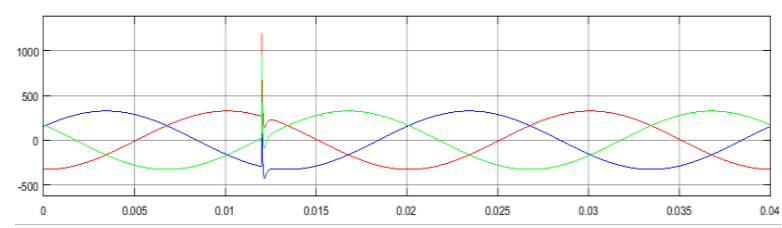

Figure 7. The effect of the lightning strike on the instantaneous value of the line voltage

The amplitude of the overvoltage surge could cause damage to the consumer equipment considered in Chapter 5 - S.C. R.T. Measuring \& Controlling S.R.L., especially of those ITs most sensitive to overvoltages caused by atmospheric electrical discharges. The effect of the simulated overvoltage resembles that of the consumer and from the discussions with the decision-makers within the company as well as from the consultation of the databases of the National Meteorological Administration it was found that during the record of the damage no weather phenomena of the type presented above, namely atmospheric electrical discharges.

\section{TRANSFORMER LOAD}

The circuit in figure 8 simulates the influence of the shock shock caused by the transformer's loading of the magnetic core saturation. The switching block is open in second and closes at $0.06 \mathrm{~s}$, simulating the voltage gap caused by transformer load.

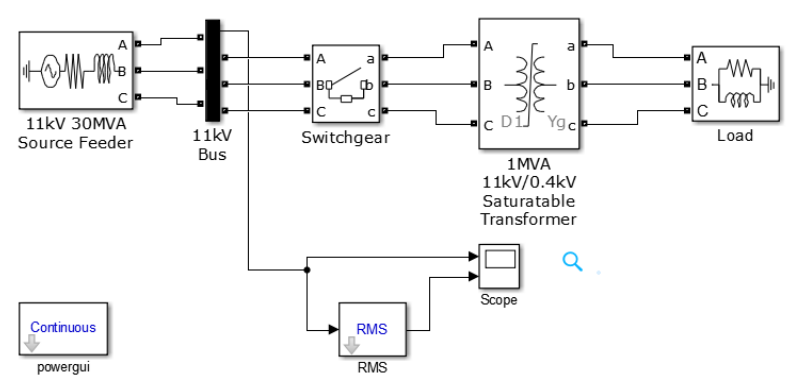

Figure 8. Circuit for simulating transformer load

Figure 9 shows the voltage gaps caused by transformer charging in Figure 8. The simulation time was set to $0.8 \mathrm{~s}$ to maintain the waveform visibility in Figure 9.a. For the given circuit, line voltages reach nominal values after 
approximately 4 seconds. It is also noted that the three phases are affected differently by the transformer charge, the largest gap being observed at Phase A.

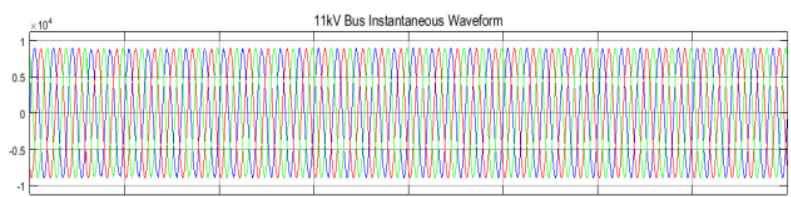

(a) Instantaneous voltage

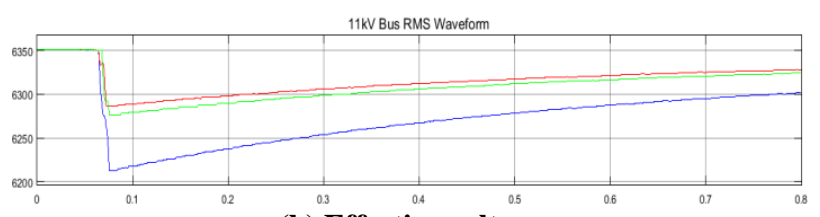

(b) Effective voltage

Figure 9. Effect of transformer charge on line voltage

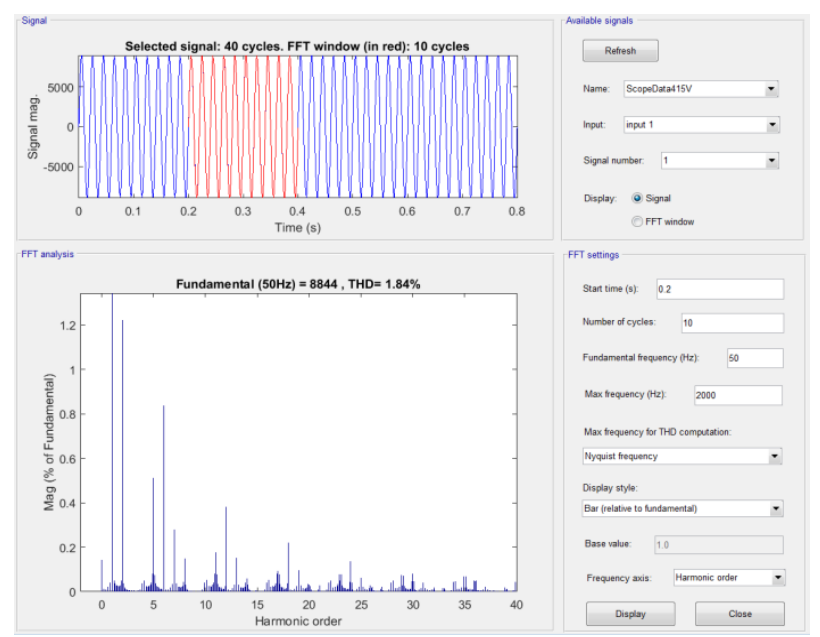

Figure 10. Harmonic analysis of distortions induced by transformer charging

Next, the Powergui module is used to visualize the Phase A signal harmonics during transformer charging. The harmonics for the simulation period of $0.2-0.4 \mathrm{~s}$ are shown in Figure 10 (together with the Powergui module configuration). In this figure we can see high harmonics, of order 2, 6, 18 and 24, typical disturbances when charging a transformer.

\section{LOADING A CAPACITOR BATTERY}

Voltage disturbances caused by charging a capacitor battery are simulated with the circuit shown in Figure 1. Each capacitor battery is connected to the bus through a circuit breaker with three phases.

The bank connected before the transformer has a $100 \mathrm{kVAR}$ capacities, and the transformer is $40 \mathrm{kVAR}$. They can compensate for a power factor of up to 0.857 corresponding to an inductive load of 100kVAR.

The timer of the simulation starts with $0.1 \mathrm{~s}$, and both sets of conggers (before and after the transformer) start charging at $0.023 \mathrm{~s}$ by switching the status of their switches. The results of this experiment are shown in
Figure 12. We notice the occurrence of voltage fluctuations over a period of $0.03 \mathrm{~s}$ (the attenuation speed being controlled by the current load). At the consumer, this disturbance resulted in pulses, the instantaneous voltage reaching a maximum of $540 \mathrm{~V}$.

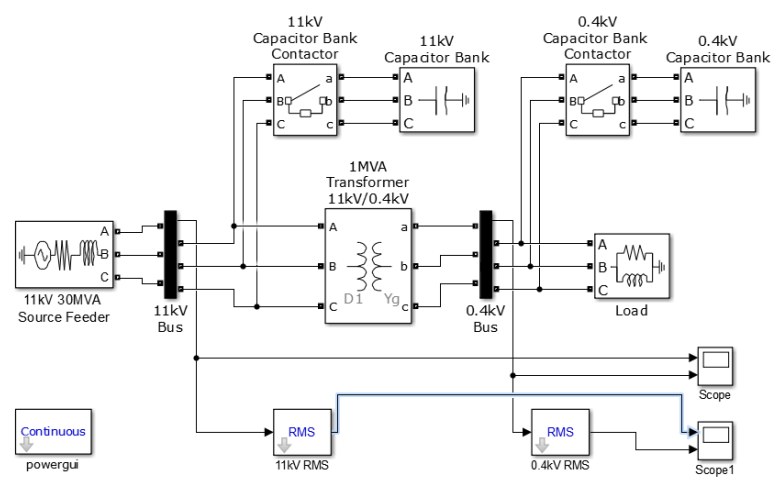

Figure 11. Circuit built to simulate charging a capacitor battery
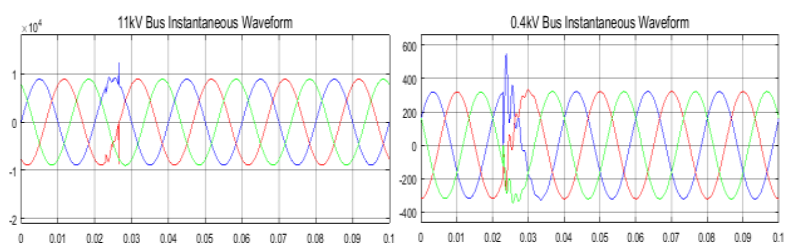

(a) Instantaneous voltage

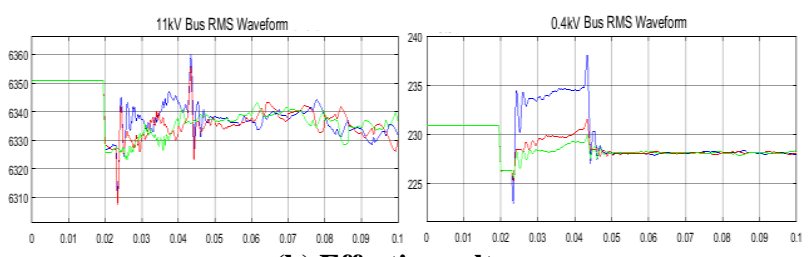

(b) Effective voltage

Figure 12. The effect of charging a number of capacitor batteries on line voltage

\section{STARTING A HIGH-POWERED ENGINE}

Figure 13 shows the circuit used to simulate the start of a high power engine. An interrupt block is also used to connect the motor to the circuit. The simulation time is set to $0.4 \mathrm{~s}$, the motor feed starts at $0.1 \mathrm{~s}$. This simulation initially uses a $75 \mathrm{~kW}$ motor, then the experiment is repeated for one of $100 \mathrm{~kW}$. Engine speed is set to one radian per second.

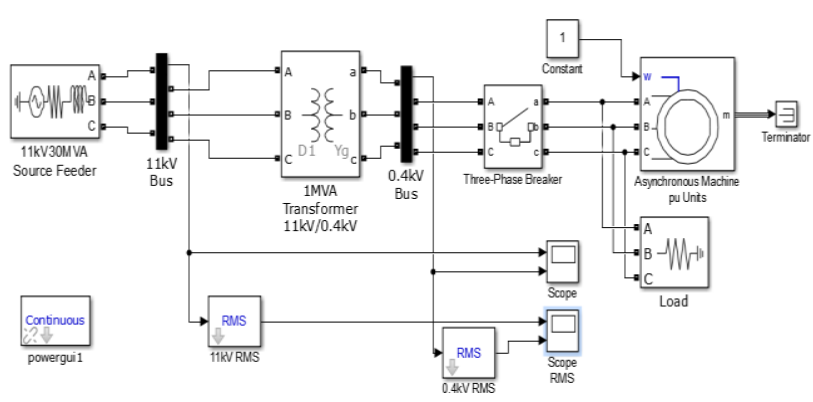

Figure 13. Circuit designed to simulate the start of a high power engine 
The effect of starting the $75 / 100 \mathrm{~kW}$ motors on the line voltage is shown in Figures 14 and 15. The voltage drop caused by the engine start was propagated through the transformer, which is also visible on the $11 \mathrm{kV}$ bus, but the effects on it are negligible. For the $75 \mathrm{~kW}$ motor, the effective voltage on this bus goes down to a minimum of about $6240 \mathrm{~V}$ (phase C) from a nominal value of $6350 \mathrm{~V}$. And at the $100 \mathrm{~kW}$ motor, the effective voltage drops to a minimum of $6190 \mathrm{~V}$.

The gap voltage magnitude is determined using the nominal motor power. A high rated motor will cause a more significant gap compared to a lower rated power. This aspect is also reflected in the graphs of Figures 14 and 15. The starting of the $75 \mathrm{~kW}$ engine made the effective voltage to the consumer reach the minimum value of $208 \mathrm{~V}$ from the nominal value of $230 \mathrm{~V}$. The start of the $100 \mathrm{~kW}$ engine produced the appearance of a minimum effective voltage of 202 volts.
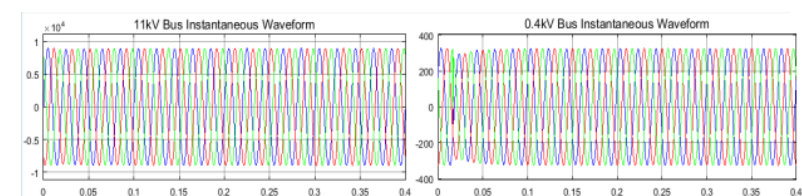

(a) $75 \mathrm{~kW}$ engine

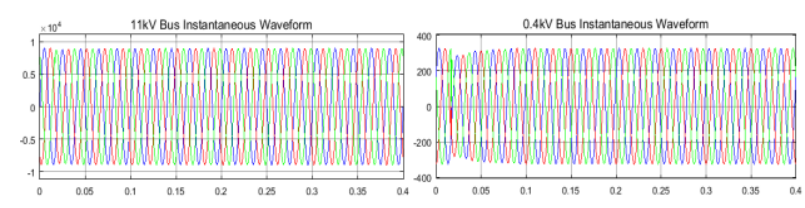

(b) $100 \mathrm{~kW}$ engine

Figure 14. Instantaneous line voltage value before and after the transformer when starting a high power motor

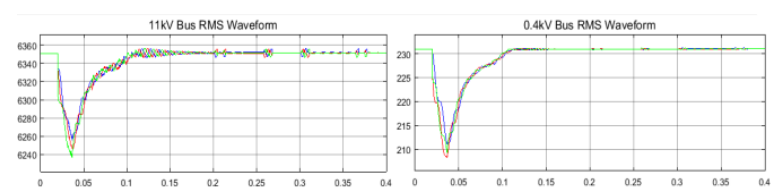

(a) $75 \mathrm{~kW}$ engine

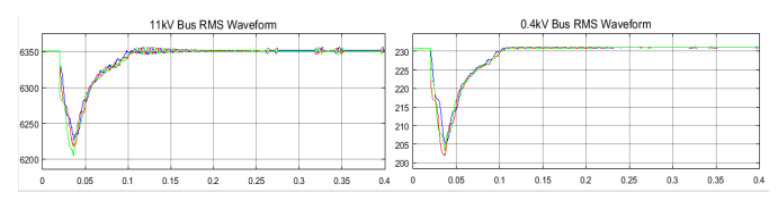

(b) $100 \mathrm{~kW}$ engine

Figure 15. Actual value of line voltage before and after the transformer when starting a high power motor

\section{USE OF FURNACE WITH ELECTRIC ARC MELTING TECHNOLOGY}

The MATLAB / Simulink environment does not have in basic modules a simulation model for a furnace with electric arc. The model should be made separately using the basic blocks in the Simulink bookstore. Next, the proposed simulation model will be implemented in [27], a model based on the diagrams of [42-50]. The corresponding circuit is shown in Figure 16.a and the sub-circuit that forms the electric arc melting furnace module is shown in Figure 16.b.

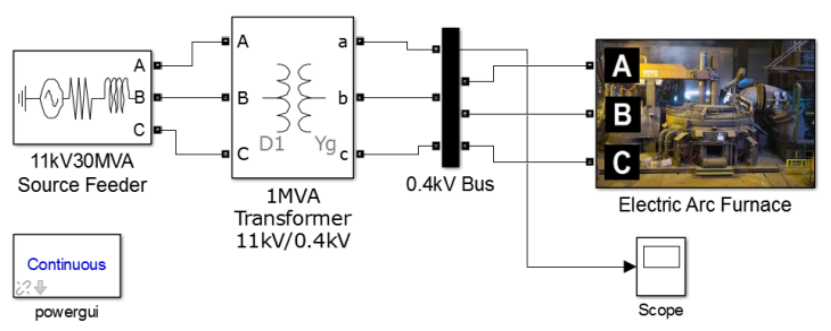

(a) Main circuit

(b)

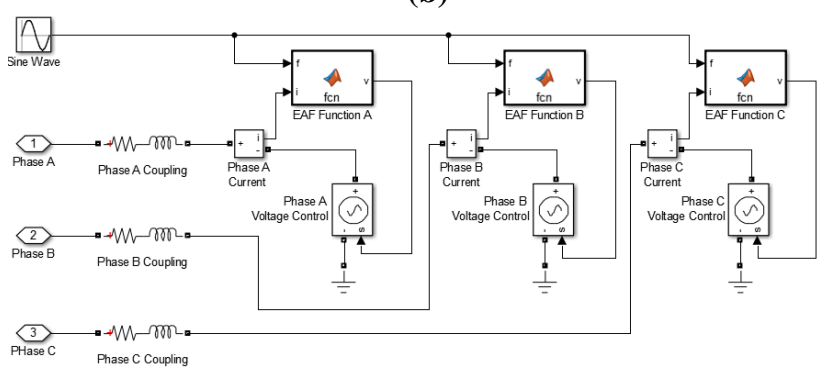

(b) The sub-circuit for the furnace

Figure 16. Circuit for simulating an electric arc melting furnace

The sub-circuit in Figure 16.b contains three voltage controlled sources (one for each phase) and three consumers having a resistive component of $0.01 \Omega$ and an inductive one of $1 \mathrm{mH}$ (one consumer for each phase). The sub-circuit also contains three MATLAB function blocks that control voltage sources depending on the current intensity on the core phase and a sinusoidal signal received from a wave generator. The sinusoidal signal has a frequency of approximately $8.8 \mathrm{~Hz}(55.3 \mathrm{rad} / \mathrm{s})$, and the function-type blocks contain the code:

$$
\begin{gathered}
\text { function v=function_EAF(f,i) } \\
\mathrm{c}=19000 ; \\
\mathrm{d}=5000 ; \\
\mathrm{m}=0.2 ; \\
\mathrm{vp}=200 ; \\
\mathrm{vt}=\mathrm{vp}+(1+(\mathrm{m} * \mathrm{f})) ; \\
\mathrm{v}=\operatorname{sign}(\mathrm{i}) *(\mathrm{vt}+(\mathrm{c} /(\mathrm{d}+\mathrm{abs}(\mathrm{i})))) ;
\end{gathered}
$$

where " $\mathrm{f}$ " is the value of the sinusoidal signal at that time, " $i$ " is the intensity of the electric current, "c" is the arc force, "d" is the arc current, "m" is the modulation index, "vp" is the arc voltage threshold, "vt" is the length of the arc, and "v" is the value which controls the voltage generator.

Using the arc melting furnace produces a flicker effect on the line voltage, the waveforms on the three phases of the $0.4 \mathrm{~kW}$ bus are shown in Figure 17. As can be seen from this figure, all three phases are distorted by the flicker effect caused by the arc melting furnace. 


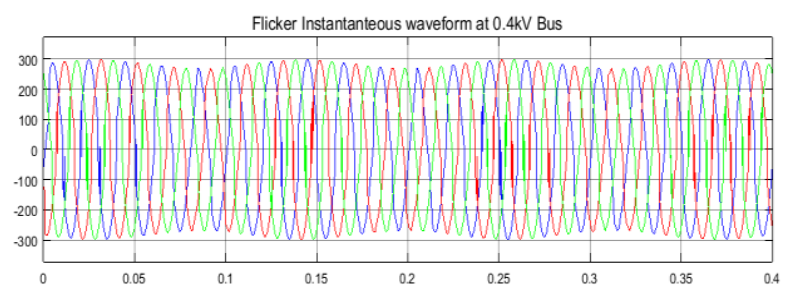

Figure 17. The effect of using the arc melting furnace on the line voltage

The disturbances on the sinusoidal waveform shown in Figure 17 (caused by the use of the electric arc furnace) also introduce harmonic distortions. These distortions are clearly visible in the spectral analysis graph shown in Figure 18. To achieve this graph, the Powergui module was used that captured data with the start of the simulation for 10 cycles, following frequencies up to 2 $\mathrm{kHz}$. There are large 3, 5, 7, 9, 11 and 13 magnitude harmonics, with the maximum at the $3 \mathrm{rd}$ order harmonics.

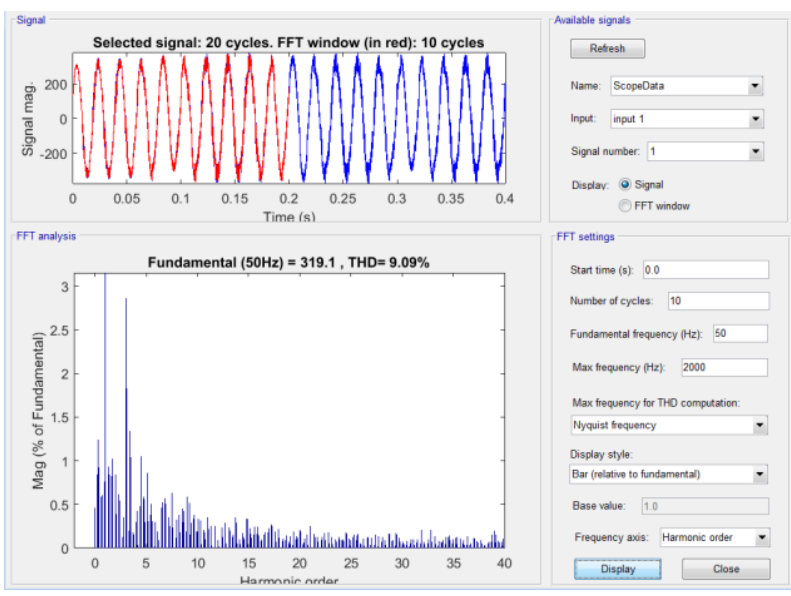

Figure 18. Harmonic analysis of distortions induced by the use of an electric arc melting furnace

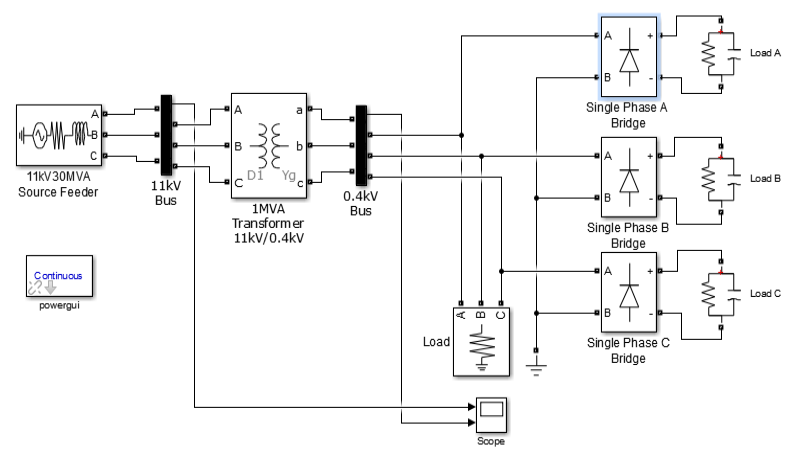

Figure 19. Circuit built to simulate a single-phase nonlinear load

\section{PRESENCE OF A SINGLE-PHASE NON- LINEAR ELECTRIC CHARGE}

To simulate disturbances produced by a single-phase nonlinear load, the circuit in Figure 19 is used. The diagram contains a single-phase capacitor rectifier with a $2 \mathrm{mF}$ capacitive filter for each phase. The diagram also contains a set of resistive consumers of $10 \Omega$. The disturbances caused by the non-linear load on the line voltage are shown in Figure 20. The sinusoidal waveform on the $0.4 \mathrm{kV}$ bus is distorted at the points corresponding to the angles of $60^{\circ}$ and $240^{\circ}$. The disturbances caused by the single-phase nonlinear load are not visible on the $11 \mathrm{kV}$ bus, they are eliminated by the transformer.

Figure 21 shows the harmonic analysis chart obtained for the circuit of Figure 19. At the $0.4 \mathrm{kV}$ bus, the distortions are present at the odd order harmonics. The transformer reduced the magnitude of the distortions, thus at the $11 \mathrm{kV}$ bus, the distortions present in the odd order harmonics were reduced (more precisely, the ones smaller than 21) or eliminated ( 21 or higher).
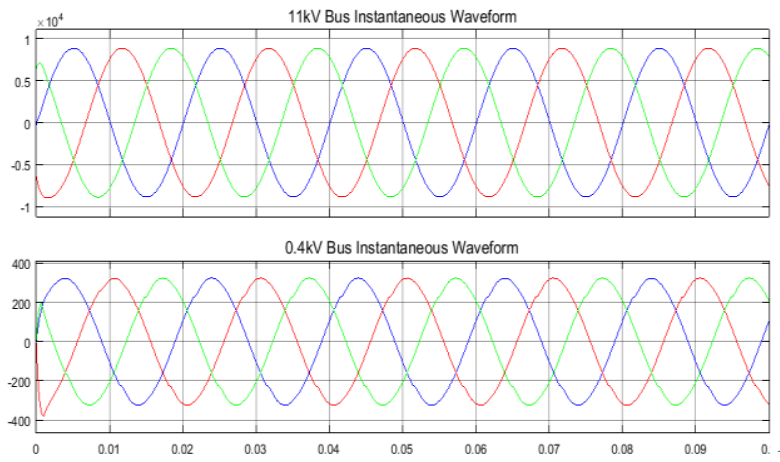

Figure 20. Effect of the presence of a one phase nonlinear load on line voltage

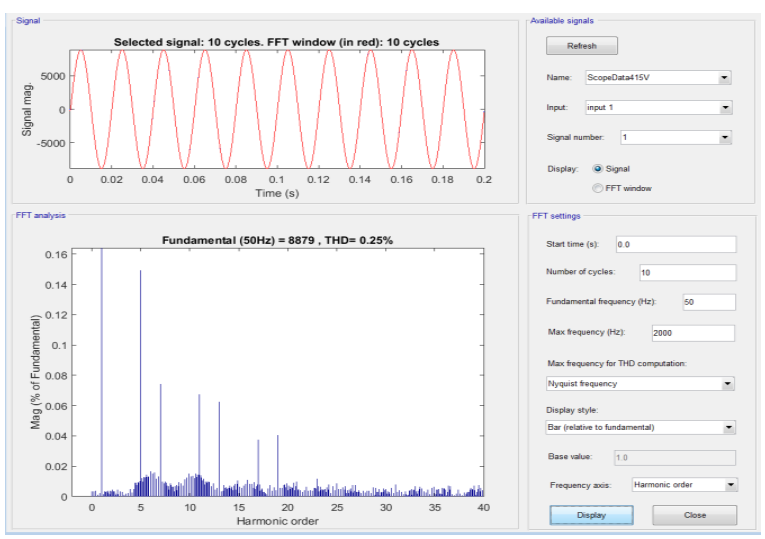

(a) Phase A on the $11 \mathrm{kV}$ bus

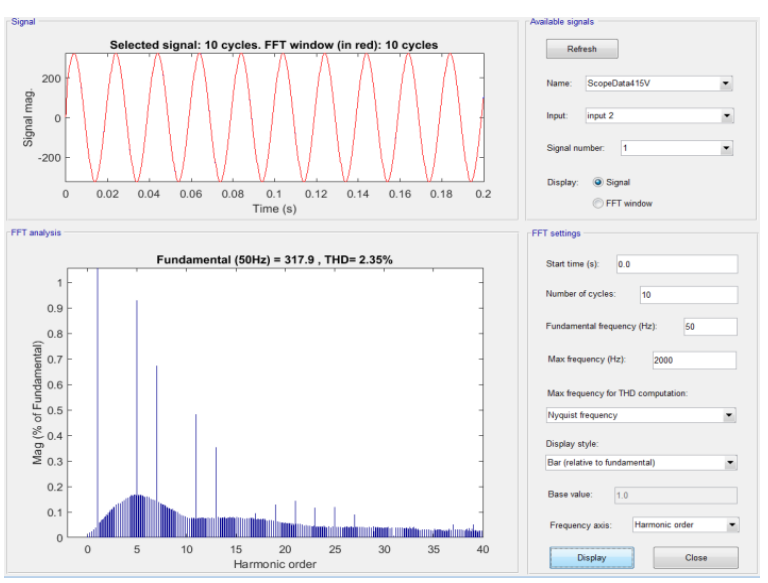

(b) Phase $A$ on the $0.4 \mathrm{kV}$ bus

Figure 21 Harmonic analysis of distortions caused by singlephase non-linear load 


\section{THE PRESENCE OF A NON-LINEAR TRI- PHASE LOAD}

The disturbances caused by a three-phase non-linear load are simulated with the circuit shown in Figure 22. The PLL (Phase Lock Loop) is used to synchronize the pulse generator, a generator that controls a three-phase rectifier. The control angle of this rectifier is controlled by a variable block with an initial value of $30^{\circ}$.

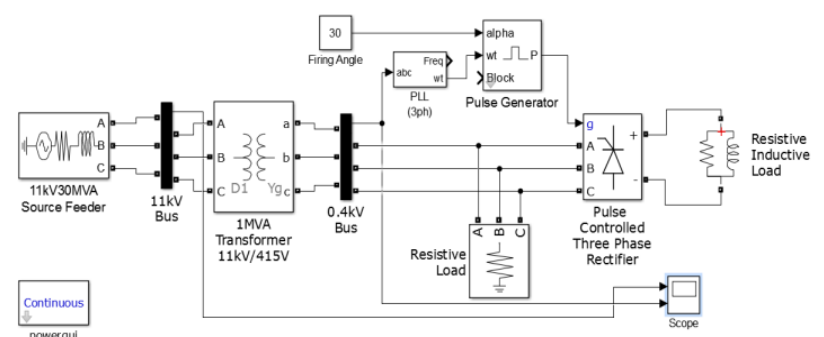

Figure 22. Circuit for simulating non-linear load on a threephase electric circuit

The disturbances introduced by the three-phase nonlinear load are shown in Figure 24. At the consumer, all three phases present pulse of line voltage. Similar to previous consumer disturbances, distortions caused by the threephase nonlinear load are attenuated by the transformer. Thus, these disturbances present on the $11 \mathrm{kV}$ bus have an attenuated aspect compared to those on the $0.4 \mathrm{kV}$ bus. The position of the voltage pulses is determined by the three-phase rectifier's control angle, and their width is determined by the inductive load in the circuit.

To visualize the harmonic distortions produced by the pulses in Figure 23.a, a harmonic analysis of the line voltages on the two bus lines is performed. The results are shown in Figure 24.

Harmonics in the order of 5, 7, 11, 13, 17, 19, 23, 25, 29, 31,35 and 37 of Phase A of the $0.4 \mathrm{kV}$ bus show strong distortions. These are also present in the case of the $11 \mathrm{kV}$ bus, but their magnitude has been significantly reduced by the passage through the transformer.
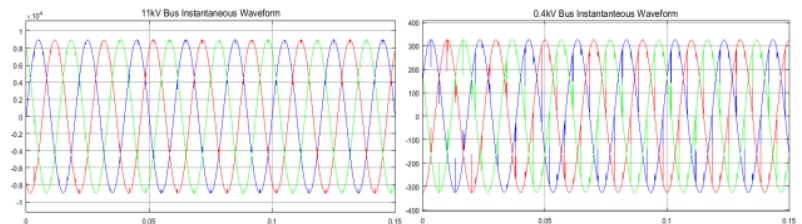

(a) three-phase rectifier control angle of $30^{\circ}$

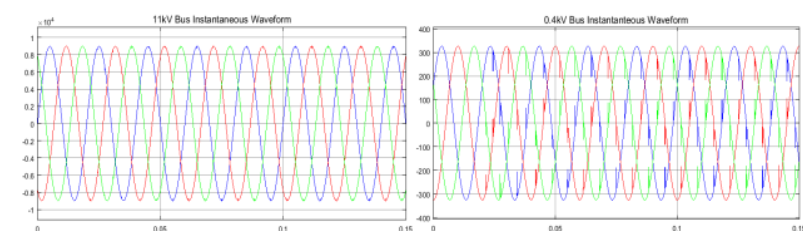

(b) three-phase rectifier control angle of $60^{\circ}$

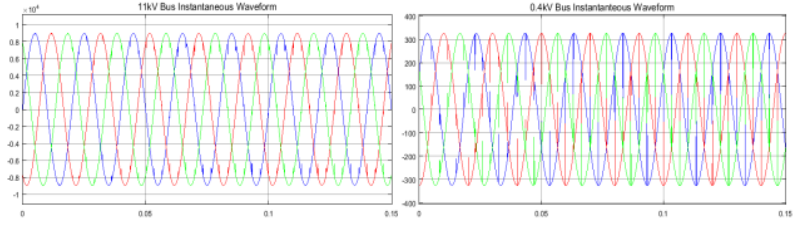

(c) three-phase rectifier control angle of $90^{\circ}$

Figure 23. The effect of the presence of a three-phase nonlinear load on the line voltage

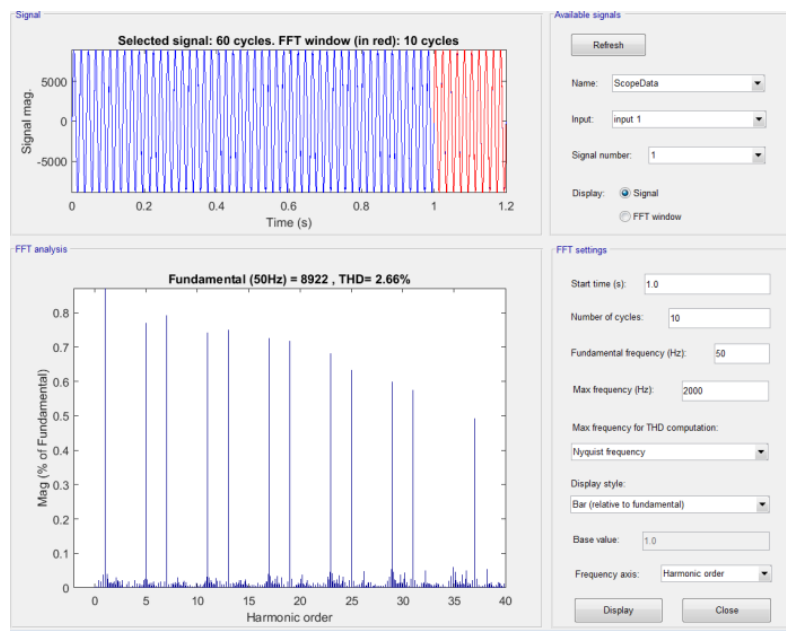

(a) Phase A on the $11 \mathrm{kV}$ bus

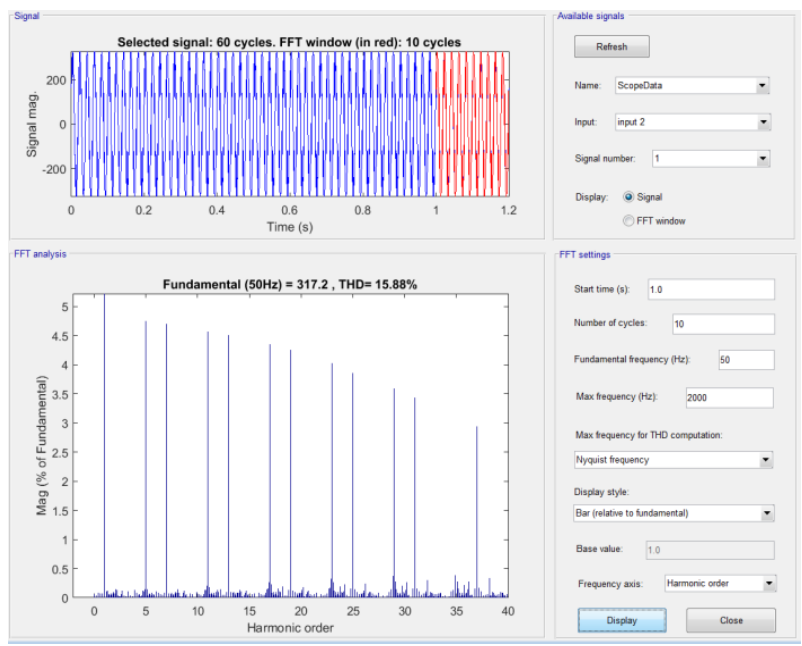

(b) Phase $\mathrm{A}$ on the $0,4 \mathrm{kV}$ bus

Figure 24. Harmonic analysis of the distortions caused by the nonlinear load on a three-phase circuit

\section{CONCLUSIONS}

The simulations offer the opportunity for the researcher to create different energy system models in order to simulate power quality deviations by connecting different functional blocks into the environment of the simulation.

Therefore, within the simulated model, it provides a perspective on the way quality deviations propagate and behave.

The limitations of the simulation is characterized by the performance of the software chosen, as well as by the 
basic knowledge of the engineer or research team on energy quality.

This article presents simulation models that are capable of simulating energy quality disturbances, including short circuit, overvoltages caused by a lightning strike, charging the transformer, charging a capacitor battery, starting a high power engine, using a melting furnace in the electric arc, the presence of a non-linear load single phase and three-phase respectively.

These simulation models have tried to present them as basic models for studying energy quality.

\section{REFERENCES}

[1] Filho J.M.C., ș.a. - „Validation of Voltage Sag Simulation Tools: ATP and Short Circuit Calculation Versus Field Measurements". IEEE Transactions on Power Delivery 23, pag. 14721480, 2008.

[2] Voltage Sags Indices, IEEE Std. P1564 draft 6, Jan. 2004.

[3] J. M. C. Filho, J. P. G. Abreu, R. C. Leborgne, T. C. Oliveira, D.M. Correia, and J.F. Oliveira, "Comparative analysis between mea-surements and simulations of voltage sags," presented at the 10th IEEE Power Eng. Soc. Int. Conf. Harmonics Quality of Power, Rio deJaneiro, Brazil, Oct. 2002.

[4] J. M. C. Filho, J. P. G. Abreu, H. Arango, and J. C. C. Noronha, "Electric power system under voltage sag: A tool for achieving compatibility," in Proc. 9th IEEE Power Eng. Soc. Int. Conf. Harmonics Qualityof Power, Orlando, FL, Oct. 2000, vol. 3, pp. 784-789.

[5] J. M. C. Filho, J. P. G. Abreu, T. C. Oliveira, O. A. S. Carpinteiro, C.B. R. Junior, F. A. Oliveira, R. P. Gomes, S. G. Carvalho, and D. N.Gonçalves, "A software for voltage sags strategic studies," presented atthe 11th IEEE Power Eng. Soc. Int. Conf. Harmonics Quality of Power,Lake Placid, NY, Sep. 2004.

[6] Patne N.R., Thakre K.L. - „Stochastic Estimation of voltage Sag Due to Faults in the Power System by Using PSCAD/EMTDC Software as a Tool for Simulation", Journal of Electrical Power Quality and Utilisation 13, pag. 59-63, 2007.

[7] Bollen M.H.J., Understanding Power Quality Problems; Voltage Sags and interruptions. ser. IEEE Press Series on Power Engineering, Piscataway, NJ, 2000.

[8] Juarez E.E., Hernandez A.: An analytical approach for stochastic assessment of balanced and unbalanced voltage sags in large system. In IEEE Transaction on Power Delivery, Vol.21, No.3, July 2006.

[9] Moschakis M.N., Hatziargyriou N.C.: Analytical calculation and stochastic assessment of voltage sags. IEEE Transaction on Power Delivery, Vol.21, No., July 2006.
[10] Anaya - Lara O., Acha E.: Modeling and Analysis of Custom Power Systems by PSCAS/EMTDC. IEEE transaction on Power Delivery,Vol.17,No.1, January 2002.

[11] Hadi S. - „Power System Analysis”, McGraw Hill, 2004.

[12] Ntombela M., ș.a. - „An Investigation into the Capabilities of MATLAB Power System Toolbox for Small Signal Stability Analysis in Power Systems", IEEE PES Conference and Exposition, 2005.

[13] J. G. Slootweg, J. Persson, A. M. van Voorden, G. C. Paap, W. L. Kling, A Study of the Eigenvalue Analysis Capabilities of Power System Dynamics Simulation Software, 14 PSCC, Sevilla, $24-28$ June, 2002.

[14] J. Persson, J. G. Slootweg, L. Rouco, L. SÖder, and W. L. Kling, A Comparison of Eigenvalues Obtained with Two Dynamic Simulation Software Packages, Accepted for presentation at 2003 IEEE Bologna Power Tech Conference, 23 - 26 June, Bologna, Italy, Paper 0-7803-7967-5/03.

[15] J. G. Slootweg, J. Persson, A. M. van Voorden, G. C. Paap, W. L. Kling, A Study of the Eigenvalue Analysis Capabilities of Power System Dynamics Simulation Software, 14 PSCC, Sevilla, 24 - 28 June, 2002.

[16] Milano F. - „An Open Source Power System Analysis Toolbox", IEEE Transaction on Power Systems 20, pag. 1199-1206, 2005.

[17] Vanfretti L., Milano F. - „Application of the PSAT, an Open Source Software for Educational and Research Purposes", IEEE PES General Meeting, 2007.

[18] M. Larsson, "ObjectStaban educational tool for power system stability studies", IEEE Trans. Power Syst., vol. 19, no. 1, pp. 56-63, Feb. 2004.

[19] J. H. Chow, K. W. Cheung, "A toolbox for power system dynamics and control engineering education and research", IEEE Trans. Power Syst., vol. 7, no. 4, pp. 1559-1564, Nov. 1992.

[20] A. H. L. Chen, C. O. Nwankpa, H. G. Kwatny, X. Yu, "Voltage stability toolbox: an introduction and implementation", Proc. 28th North American Power Symp., Nov. 1996.

[21] F. Milano, PSAT Matlab-Based Power System Analysis Toolbox, 2002.

[22] M. Kezunovic, G. H. A. Abur, A. Bose, and K. Tomsovic, "The Roleof Digital Modeling and Simulation in Power Engineering Education,"in IEEE Transactions on Power Systems, no. 1, Feb. 2004, pp. 64-72.

[23] J. Chow, F. F. Wu, and J. Momoh, Applied Mathematics for RestructuredElectric Power Systems. Springer-Verlag, 2005, reference in Chapter 8, Instability Monitoring and Control of Power Systems, by E. H. Abed,M. A. Hassouneh and M. S. Saad.

[24] Sybille G., Hoang L.H. - „Digital Simulation of Power Systems and Power Electronics using the 
MATLAB/Simulink Power System Blockset", IEEE PES Winter Meeting 4, pag. 2973-2981, 2000.

[25] Sybille G., ș.a. - „Theory and Applications of Power System Blockset, A MATLAB/Simulink-Based Simulation Tool for Power Systems", IEEE PES Winter Meeting 1, pag. 774-779, 2000.

[26] Dessaint L.A., ș.a. - „A Power System Simulation Tool Based on Simulink", IEEE Transactions on Industrial Electronics 46, pag. 1252-1254, 1999.

[27] Tan, R.H.G., Ramachandaramurthy V.K. - ,A Comprehensive Modeling and Simulation of Power Quality Disturbances Using MATLAB/SIMULINK", Power Quality Issues in Distributed Generation. InTech, 2015.

[28] W. Long et al., "EMTP a powerful tool for analyzing power system transients," IEEE Comput. Appl. Power, vol. 3, pp. 36-41, July 1990.

[29] Fried, S.O., Kharbawe, N. E., A. Edris, 2010. The use of static Compensator for improving power system stability in response to selective pole Switching, IEEE-ISGT Europe, pp. 1-6.

[30] Ghamgeen Izat Rashed, Yuanzhang Sun, Optimal Placement of Thyristor Controlled Series Compensation for Enhancing Power System Security Based on Computational Intelligence Techniques, Procedia Engineering, Vol. 15, pp. 908914, 2011

[31] Ghamgeen,I. Rashed, H. I. Shaheen, S. J. Cheng, 2007. Optimal location and parameter setting of TCSC by both Genetic Algorithm and Particle Swarm Optimization, IEEE conference on Industrial Electronics and Application, pp. 1141-1147.

[32] McGranaghan M, Roettger B (2002) Economic Evaluation of Power Quality, IEEE Power Engineering Review, 22: 8-12.

[33] McGranaghan M, Santoso S (2007) Challenges and Trends in Analyses of Electric Power Quality Measurement Data, EURASIP Journal on Advances in Signal Processing.

[34] McEachern A (2007) A Free Simulator Program for Teaching Power Quality Concepts, 9th International Conference Electrical Power Quality and Utilisation.

[35] Bam L, Jewell W (2005) Review: Power System Analysis Software Tools, IEEE PES General Meeting 1: 139-144.

[36] Guzman, A; Mooney, J. B; Benmouyal, G; Fischer, N. (2002), Transmission Line Protection System for Increasing Power System Requirements. 55th Annual Conference for Protective Relay Engineers, College Station, Texas, (April 2002).

[37] Schoder K., ș.a. - „PAT: A Power Analysis Toolbox for MATLAB/Simulink". IEEE Transactions on Power Systems 18, pag. 42-47, 2003.

[38] E. Allen, N. LaWhite, Y. Yoon, J. Chapman, M. Ilić (Ilic), "Interactive object-oriented simulation of interconnected power systems using simulink", IEEE Trans. Educ., vol. 44, pp. 87-95, Feb. 2001.

[39] K. Schoder, A. Hasanović (Hasanovic), A. Feliachi, "Load-flow and dynamic model of the Unified
Power Flow Controller (UPFC) within the Power System Toolbox (PST)", Proc. IEEE Midwest Symp. Circuits Syst., 2000.

[40] K. Schoder, A. Hasanović (Hasanovic), A. Feliachi, "Power system damping using fuzzy controlled unified power flow controller", Proc. IEEE Power Eng. Soc. Winter Meeting, 2001.

[41] Bam L., Jewell W. - „Review: Power System Analysis Software Tools", IEEE PES General Meeting 1, pag. 139-144, 2005.

[42] Bhonsle D.C., Kelkar R.B. - „Simulation of Electric Arc Furnace Characteristics for Voltage Flicker Study using MATLAB", International Conference on Recent Advancements in Electrical, Electronics and Control Engineering, pag. 174-181, 2011.

[43] Rahmatallah Hooshmand, Mahdi Banejad and Mahdi Torabian Esfahani, "A New Time Domain Model for Electric Arc Furnace", Journal of Electrical Engineering, Vol. 59, No. 4, 195-202, 2008.

[44] Mahdi Banejad, Rahmat-Allah Hooshmand and Mahdi Torabian Esfahani, "Exponential-Hyperbolic Model for Actual Operating conditions of Three Phase Arc Furnaces", American Journal of Applied Scinces 6 (*): 1539-1547, 2009.

[45] Abou El Ela, A.A., Abido, M.A., Spea, S.R. 2010. Optimal power flow using differential evolution algorithm, Electric Power Systems Research, Vol. 80, pp. 878-885.

[46] Golkar M.A., Tavakoli Bina M., Meschi S. - ,A Novel Method of Electrical Arc Furnace Modeling for Flicker Study", International Conference on Renewable Energies and Power Quality, pag. 1-8, 2007.

[47] TongxinZheng, ElhamB.Makram, AdlyA.Girgis. "Effect of Different Arc Furnace Models on Voltage Distortion", IEEE 1998.

[48] Omer Ozgun, Ali Abur, "Development of an Arc Furnace Model for Power Quality Studies", IEEE, 1999.

[49] Omer Ozgun, Ali Abur, "Flicker Study Using a Novel Arc Furnace Model", IEEE transaction on power delivery Vol.17, No.4, 2002.

[50] Zheng T., Makram E. B. and Girgis A. A., "Effect of different arc furnace models on voltage distortion", IEEE Transactions, International Conference on Harmonics and Quality of Power, 14-18 October 1998, Volume 2, pp. 1079-1085.

[51] www.mathworks.com/matlabcentral/fileexchange/ 